\title{
Review Article \\ Regulation of Synthesis and Roles of Hyaluronan in Peritoneal Dialysis
}

\author{
Timothy Bowen, ${ }^{1}$ Soma Meran, ${ }^{1}$ Aled P. Williams, ${ }^{1}$ Lucy J. Newbury, \\ Matthias Sauter, ${ }^{2,3}$ and Thomas Sitter ${ }^{2}$ \\ ${ }^{1}$ Wales Kidney Research Unit, School of Medicine, College of Biomedical and Life Sciences, Cardiff University, Heath Park, \\ Cardiff CF14 4XN, UK \\ ${ }^{2}$ Medizinische Klinik und Poliklinik IV, Klinikum der Universität München, Ziemssenstrasse 1, 80336 München, Germany \\ ${ }^{3}$ Klinikum Kempten, Robert-Weixler-Strasse 50, 87439 Kempten, Germany
}

Correspondence should be addressed to Timothy Bowen; bowent@cf.ac.uk

Received 22 June 2015; Accepted 16 August 2015

Academic Editor: Robert Beelen

Copyright (C) 2015 Timothy Bowen et al. This is an open access article distributed under the Creative Commons Attribution License, which permits unrestricted use, distribution, and reproduction in any medium, provided the original work is properly cited.

\begin{abstract}
Hyaluronan (HA) is a ubiquitous extracellular matrix glycosaminoglycan composed of repeated disaccharide units of alternating $\mathrm{D}$-glucuronic acid and $\mathrm{D}-\mathrm{N}$-acetylglucosamine residues linked via alternating $\beta-1,4$ and $\beta-1,3$ glycosidic bonds. HA is synthesized in humans by HA synthase (HAS) enzymes 1, 2, and 3, which are encoded by the corresponding HAS genes. Previous in vitro studies have shown characteristic changes in HAS expression and increased HA synthesis in response to wounding and proinflammatory cytokines in human peritoneal mesothelial cells. In addition, in vivo models and human peritoneal biopsy samples have provided evidence of changes in HA metabolism in the fibrosis that at present accompanies peritoneal dialysis treatment. This review discusses these published observations and how they might contribute to improvement in peritoneal dialysis.
\end{abstract}

\section{Hyaluronan: Multiple Functions and Clinical Significance}

Hyaluronan (HA) is a linear glycosaminoglycan associated most commonly with the extracellular matrix (ECM). HA was first isolated from the optic vitreous [1] and is composed of tandem repeats of a D-glucuronic acid and D$\mathrm{N}$-acetylglucosamine disaccharide motif linked via alternating $\beta-1,4$ and $\beta-1,3$ glycosidic bonds [2]. Unique amongst glycosaminoglycans, $\mathrm{HA}$ is unsulfated and contains no epimerised uronic acid residues. To export HA to the ECM, the HA synthase (HAS) proteins traverse the plasma membrane and act as glycosyltransferases, combining precursor UDP-glucuronic acid and UDP-N-acetylglucosamine to form HA. HA polymers are thus synthesised at the HAS active site on the intracellular side of the membrane and exported instantaneously as linear, unaltered polymers [3].

HA was thought initially to be an inert, space-filling molecule [4]. More recent analyses, however, have shown that $\mathrm{HA}$ is a multifunctional molecule for which a number of key roles have already been identified during and following development. These inter- and intracellular functions include roles in cell migration, tumour invasion, and cellular response to injury (e.g., [5-10]).

The importance of HA in the ECM is underlined by the expanding range of pathological contexts in which modified or aberrant HA metabolism appears to play a role. These include autoimmune renal injury, fibrosis of the kidney and other large organs, diabetic nephropathy, malignancy, osteoarthritis, and pulmonary and vascular disorders, along with other immune and inflammatory diseases (e.g., [6, 930]). HA deposition is characteristic of peritoneal fibrosis subsequent to dialysis treatment [31, 32]. HA has also been implicated in regenerative processes such as wound healing in the peritoneum and elsewhere [33-39] and as a key immune mediator [20, 21]. Upregulation of HA synthesis has also been reported in inflammation that occurs commonly as a consequence of treatment of renal failure by peritoneal dialysis (PD) $[32,33]$. The focus of this review will be on the regulation and function of $\mathrm{HA}$ in $\mathrm{PD}$. 


\section{Regulation of HA Synthase (HAS) Expression}

$\mathrm{HA}$ is synthesised by the enzymes HAS1-3. These proteins are encoded by the corresponding HAS genes HAS1, HAS2, and $H A S 3$, with each human gene located at a discrete autosomal locus [40].

The human peritoneal mesothelial cells (HPMCs) that line the peritoneal membrane synthesise HA as a normal constituent of peritoneal effluent, and this synthesis is upregulated during periods of peritonitis [41]. In an in vitro model of peritoneal wound healing [42], mechanical disruption of HPMC monolayers led to upregulated HAS2 transcription together with an increase in HA synthesis [33].

However, despite the above array of pathological and physiological functions already ascribed to HA, comparatively little is known about the regulation of human HAS expression in peritoneal inflammation and fibrosis.

We began our studies on the regulation of HAS expression by defining genomic structures for each human $H A S$ gene [43]. As part of this study, we prepared luciferase reporter constructs spanning approximately $0.5 \mathrm{~kb}$ of genomic DNA upstream of each putative HAS transcription start site (TSS) $[43,44]$. Each sequence showed significant promoter ability to drive transcription of the luciferase gene [43].

To locate the HAS2 promoter, we carried out HAS2specific $5^{\prime}$-rapid amplification of cDNA ends ( $5^{\prime}$ RACE) on polyadenylated RNA extracted from renal proximal tubular epithelial cells and located the TSS $0.130 \mathrm{~kb}$ upstream of the $5^{\prime}$ end of HAS2 reference mRNA sequence NM_005328 [45]. We then generated luciferase reporter vectors bearing nested fragments spanning the first $0.8 \mathrm{~kb}$ upstream of this new TSS $[45,46]$. Luciferase analysis showed consistent promoter activity mediated by a minimum-sized fragment of $0.121 \mathrm{~kb}$, within which we identified promoter sequences conserved in selected mammals $[45,46]$. Similar methods have recently been used to identify the human HAS3 promoter [47].

Using electrophoretic mobility shift and supershift data, we then demonstrated binding of transcription factors Sp1 and Sp3 to three sites immediately upstream of the HAS2 TSS [48]. Luciferase analysis of mutated reporter constructs was abrogated, while RT-qPCR analysis following siRNA knockdown of either transcription factor significantly reduced the level of HAS2 transcription [48]. Chromatin immunoprecipitation analysis of this locus has since been used to analyse HAS2 transcriptional induction by retinoic acid and tumour necrosis factor- $\alpha$ [49].

The tetraexonic, long noncoding RNA transcript HAS2AS1 is transcribed from the opposite genomic DNA strand to HAS2 mRNA at 8q24.13 [50]. The second exon of HAS2AS1 shares partial sequence complimentary with HAS2 exon 1, and HAS2-AS1 can therefore be described as a "natural antisense" to HAS2 [50]. In osteosarcoma cells, transcription of HAS2 mRNA synthesis and subsequent HA production are downregulated by HAS2-AS1 [50]. By contrast, in renal proximal tubular epithelial cells, we showed that HAS2AS1 expression augments and/or stabilises HAS2 mRNA and detected cytoplasmic HAS2:HAS2-AS1 RNA duplexes [51]. In aortic smooth muscle cells, HAS2-AS1 also upregulates HAS2 expression and mediates posttranscriptional modification of HAS2 by O-GlcNAcylation [52].

We have also identified the HAS1 TSS, adding a further 26 nucleotides to reference sequence NM_001523, and analysed the upstream HAS1 promoter region in renal proximal tubular epithelial cells $[46,53]$, but a full characterisation of factors regulating HAS expression in HPMCs has not been carried out. In addition, little is known about HPMC expression of long noncoding RNAs (including HAS2-AS1) and of microRNAs, both of which are highly likely to regulate HAS expression. Indeed, understanding the transcriptional and posttranscriptional mechanisms regulating HPMC HAS expression will provide useful information on the control of HA synthesis during PD and has the potential to inform future approaches to antifibrotic PD therapy.

\section{Synthesis of HA by Peritoneal Mesothelial Cells}

HA is an important component of the HPMC ECM and is also produced by fibroblasts and macrophages in the peritoneal cavity [54-56]. According to in vivo findings, HA levels are increased in peritoneal dialysate during peritonitis [54]. It has also been shown in vitro that the synthesis of HA in mesothelial cells is enhanced by various inflammatory mediators including prostaglandin E2, PDGF, transforming growth factor-betal, tumour necrosis factor-alpha (TNF- $\alpha$ ), and interleukin-6 (IL-6), with IL-1 $\beta$ producing the strongest effect $[41,55,57]$.

$\mathrm{HA}$ is found predominantly in connective tissue where the polymer chain is bound to interacting molecules such as cell surface receptor CD44, the receptor for HA-mediated motility, and proteoglycans including aggrecan and versican $[58,59]$.

Under homeostasis, HA polymers are typically between 2,000 and 25,000 disaccharide units in length, and these chains have been sized at 2-25 $\mu \mathrm{m}$ [11]. Yung and Chan [32] have ably summarised much previous work on the properties and effects of low and high molecular weight HA. Despite this sizeable body of accumulated data, attribution of functions dependent on the number of disaccharide repeat units in the HA polymer remains controversial. Understanding the potential functional differences is complicated by the fact that HA can be digested by the hyaluronidase (HYAL) enzymes encoded by the HYAL multigene family [60] and by HA degradation at different sites. An early in vivo study in which radiolabelled HA was injected into rabbit knee joints showed degradation locally and in the liver [61].

The biological effects of adding exogenous HA preparations to cultured HPMCs have been studied in vitro in numerous cell culture systems. Yung and colleagues [33] showed that addition of HA accelerated in vitro healing of wounded HPMC monolayers in a dose-dependent manner between 50 and $3300 \mathrm{ng} / \mathrm{mL}$. Mediation of these proliferative HA effects by interaction with CD44 remains unproven [62]. The key role played by HA in the process of remesothelialisation was confirmed in a further in vitro model of HPMC cell migration [63]. 
When HPMCs were exposed to spent dialysates supplemented with 0.1 or $0.5 \mathrm{mg} / \mathrm{mL}$ high molecular weight $\mathrm{HA}$, synthesis of chemokine monocyte chemoattractant protein (MCP-1), adhesion molecule soluble intercellular adhesion molecule (s-ICAM), vascular endothelial cell growth factor (VEGF), and fibronectin was significantly reduced [64]. However, these differences were not observed in vivo when the same inflammatory mediators were measured in drained dialysate patient samples [64]. In accordance with the above in vitro findings, high molecular weight $\mathrm{HA}$ also inhibits the nuclear factor-kappa B- (NF- $\kappa$ B-) dependent synthesis of cytokines IL- $1 \alpha$, IL- 6 , and TNF- $\alpha$ in mouse macrophage line J774 [65].

Since HA alters the fibrinolytic properties of numerous cell types [66], we investigated the effect of HA on the synthesis of tissue plasminogen activator (tPA) and plasminogen activator-1 (PAI-1) in HPMCs. Only very high concentrations of HA ( $>50 \mathrm{mg} / \mathrm{dL})$ downregulated fibrinolytic HPMC activity by decreasing t-PA synthesis, but changes in t-PA and PAI-1 expression were not observed at concentrations up to $30 \mathrm{mg} / \mathrm{dL}$ [66]. A subsequent study has shown that monocyte/macrophage system cells interfered with HA-associated changes in the fibrinolytic capacity of HPMCs treated with lipopolysaccharide [67].

HA fragments activate nitric-oxide synthase in murine macrophages through an NF- $\kappa \mathrm{B}$-dependent mechanism, increasing expression of chemokines macrophage inflammatory protein-alpha (MIP- $1 \alpha)$, MIP-1 $\beta$, and MCP-1 [68, 69]. In renal cortical tubular cells the synthesis of adhesion molecules ICAM-1 and vascular cell adhesion protein-1 (VCAM-1), and MCP-1, were upregulated following stimulation with low molecular weight HA [70]. Similarly, we found that HA fragments of approximate molecular mass 1-7 $\times$ $10^{5} \mathrm{Da}$ induced the synthesis of the chemokines MCP-1 and IL-8 in HPMCs [71]. The upregulation of these chemokines was preceded by an increase in NF- $\kappa \mathrm{B}$ and activating protein1 DNA binding activity in HPMCs [71].

Breborowicz and coworkers found changes in HPMC synthetic activity following exposure to dialysis fluids, including downregulated HA synthesis [72]. Glutathione precursor L-2-oxothiazolidine-4-carboxylic acid prevented this effect, suggesting that it may be driven by glucose-induced free radicals during PD [72]. Chronic exposure of HPMCs to glucose or $\mathrm{N}$-acetylglucosamine showed the latter to be more biocompatible, despite the fact that it upregulated HA synthesis [73]. Treatment with peroxisome-proliferator activator receptor-gamma agonist ciglitazone decreased endometrial cell attachment to HPMC line LP9 and decreased LP9 attachment to HA-treated tissue culture plate wells [74]. HPMC senescence in vitro was accelerated by glucose but not Nacetylglucosamine [75].

In summary, the effects of in vitro HA application to HPMCs are complex and dependent on HA molecular weight. High molecular weight HA appears to have antiinflammatory and preservative effects, while low molecular weight HA stimulates proinflammatory processes. However, as several studies have failed to discriminate clearly between the effects of HA of different sizes, an unambiguous interpretation of these data is challenging, and new data will be required to resolve this issue.

\section{HA in Peritoneal and Endothelial Glycocalyces}

Emerging evidence suggests that HA at the mesothelial cell surface contributes significantly to the peritoneal glycocalyx [32, 76-78]. This structure performs a number of roles including protection and lubrication, and denudation during PD and/or injury is likely to accelerate HPMC and peritoneal damage and thereby treatment failure $[32,77]$. HA is also a key component of the endothelial glycocalyx, contributing significantly to its permeability $[79,80]$, and a recent study has investigated the potential importance of the systemic microvascular endothelial glycocalyx as a transport barrier during PD [81].

\section{Intraperitoneal In Vivo Administration of HA to Prevent Surgery-Induced Adhesions}

Postoperative adhesions are a frequent outcome of abdominal surgery and may lead to bowel obstruction, chronic pelvic pain, infertility, and technical difficulties in further surgical procedures [82]. Both in humans and in animal models, intraperitoneal (IP) administration of HA has been tested in an attempt to prevent the formation of postsurgical adhesion. Numerous HA preparations for IP application are commercially available or in development. Interpretation of the diverse outcomes following their use is not straightforward, as is clear from the studies described below.

A number of prospective randomized trials have been carried out to determine the efficacy of HA-based adhesionpreventing agents. One such study analysed the antiadhesion efficacy of a $0.5 \%$ ferric hyaluronate gel in severe peritoneal trauma caused by bipolar coagulation in a laparoscopic rat model. Adhesion scores were decreased significantly, but none of the animals was free of adhesions, and the authors did not show a significant difference between the HA gel treatment and the use of the adhesion-preventing agents Ringer's lactate solution and $4 \%$ icodextrin solution [83]. In a prospective randomized study of peritoneal laparoscopic resection in rabbits using $0.5 \%$ ferric hyaluronate gel, saline, or control, no differences in adhesion scores and number of animals with adhesions were reported [84]. By contrast, a prospective randomized multicentre study in humans showed that a glycerol$\mathrm{HA} /$ carboxymethylcellulose membrane effectively reduced intra-abdominal adhesions in patients who underwent proctocolectomy and ileal-pouch-anal anastomosis [85]. However, the increase in infectious complications caused the manufacturer not to market this product [85].

Considerable research efforts have been devoted to analysis of membranes composed of HA and carboxymethylcellulose (HA/CMC; commercially available as Seprafilm) both alone and in conjunction with additional agents, while other treatments have also been tested. For instance, Nilsson and colleagues [86] investigated the use of HAPXL01, a novel 
polypeptide derived from human lactoferrin, in the sidewalldefect cecal abrasion model in the rat [86]. An HA-based formulation of HAPXL01 inhibited scar formation, prohibiting inflammation and promoting fibrinolysis and significantly reducing adhesion formation without affecting wound healing [86].

In the first of two studies by Lim and coworkers, HA/ CMC Seprafilm mediated effective reduction in adhesion formation by peritoneal ischemic buttons created either side of a midline incision that was limited to the site of application [87]. Irrespective of the bioresorbable material at predicted adhesion sites, peritoneal adhesions formed readily at unprotected sites [87]. In a later study, coadministration of neurokinin 1 receptor antagonist significantly augmented the effect of the HA/CMC membrane on adhesion prevention from experimentally induced peritoneal ischaemic buttons, and combined use of these treatments reduced adhesion formation both at the site of application and at distal sites [88].

In a rat laparotomy/cecal injury model, IP-administered atorvastatin proved to be equally as effective as Seprafilm in the prevention of postoperative adhesion, but there was no additive effect when both treatments were combined [89].

Data on HA-based membranes has not always been positive, however. The study of Economidou and coworkers [90] set out to evaluate the effects of administration of two (unidentified) commercial membranes: a thicker membrane composed of macromolecular polysaccharides and a thinner HA-hydroacid methylcellulose-based membrane. The use of the former resulted in elevated serum creatinine and urea levels, tubular epithelial cell vacuolization, and mild interstitial infiltration [90]. These lesions were milder when the HA-based membrane was used, and serum creatinine did not change [90].

Use of HA/CMC powder and film applied either directly or contralaterally was compared in a rat peritoneal sidewall defect model and a rabbit cecal abrasion/sidewall defect model [91]. Both additives reduced adhesions to the same degree on direct application, while powder alone was effective on remote application but did not inhibit wound healing [91]. In a severe adhesion model in which $1 \mathrm{~cm}^{2}$ of intra-abdominal wall was excised and $n$-butyl-2-cyanoacrylate was applied, Hwang and colleagues [92] compared HA/sodium CMC gel (Guardix-sol), 4\% icodextrin, and Seprafilm. Scoring for both fibrosis and adhesion showed a significant reduction in both when Seprafilm alone was used [92].

A comparison of IP-administered linezolid with Seprafilm [93] found both to be significant in reducing formation of rat peritoneal adhesions following sterile antimesenteric (side) surface cecal abrasion, when compared to controls. Similarly, both IP lovastatin and Seprafilm were equally effective in preventing postoperative intra-abdominal adhesions of cecal, ileal, and uteral abrasions [94]. Observations from a rabbit model showed that the combined use of $3 \%$ trehalose solution and Seprafilm had additive effects in the prevention of adhesion formation [95]. A recent study using a biodegradable HA-based hydrogel formed in situ showed a promising and significant reduction in adhesion formation [96].
In summary, the use of a variety of HA and HA-derived preparations used in past studies complicates the process of data interpretation. However, a significant body of evidence now supports the use of HA/CMC agents, and the utility of intraperitoneally administered HA has potential for future development.

\section{Animal Studies on PD Examining In Vivo HA Application}

Where appropriate, selected data from the studies discussed below are summarized in Table 1. The therapeutic application of the addition of HA to PD fluid is based on the assumption that HA is lost from the peritoneal cavity during PD [97]. In PD patients, IP production of HA increases during episodes of peritonitis [41, 98], and with the duration of PD therapy the HA concentration rises in the effluent of PD patients [99]. Consequently, the first animal studies were performed to determine the role of $\mathrm{HA}$ in peritoneal function during PD [97]. A number of studies using IP-soluble HA administration have been described, the majority being in animal models.

6.1. Effects of HA-Containing Fluid on PD Transportation Characteristics. Significantly lower transperitoneal protein equilibration for albumin and for total protein in rats receiving a Dianeal solution containing $10 \mathrm{mg} / \mathrm{dL}$ HA twice daily for 4 weeks has been reported [97], and these data have been supported by the results of other studies [100, 101]. Furthermore, the total drained volume after a 4-hour dwell was significantly higher in the HA group, yielding a positive net ultrafiltration (UF) in the HA group versus a negative net UF in the control group [97].

The above effect was based mainly on a decreased peritoneal fluid absorption rate, which was demonstrated independently following 4-hour HA solution dwell, together with increased urea clearance [102]. The same authors showed that there was no difference in the transcapillary UF rate $(\mathrm{Qu})$ between different concentrations and various molecular weights of $\mathrm{HA}$ in control groups or even a reduced $\mathrm{Qu}$ in one $\mathrm{HA}$ group receiving $4 \mathrm{MD}$ molecular weight $\mathrm{HA}$ [103]. They also reported that the effect of HA on peritoneal fluid absorption and net UF appeared to be both sizeand concentration-dependent [104] and noted that this HAmediated effect was potentially useful to prevent a decrease in net UF caused by increased peritoneal dialysate fill volume [105]. With respect to small solute clearance, it was shown that $\mathrm{HA}$ administration resulted in a significantly increased urea clearance $[100,105]$.

Rosengren et al. [106] provided evidence that both small solute transfer and glucose-induced osmotic water transfer (using a $3.86 \%$ glucose-based solution) was not influenced by HA supplementation of dialysis fluid. HA did, however, reduce backfiltration of fluid from peritoneum to plasma by forming a "filter-cake" [106]. These researchers also found that hyaluronidase incubation resulted in a 78\% reduction of HA in the superficial layer of the peritoneal membrane which did not produce any significant changes in solute and fluid transport across the peritoneal membrane [107]. 


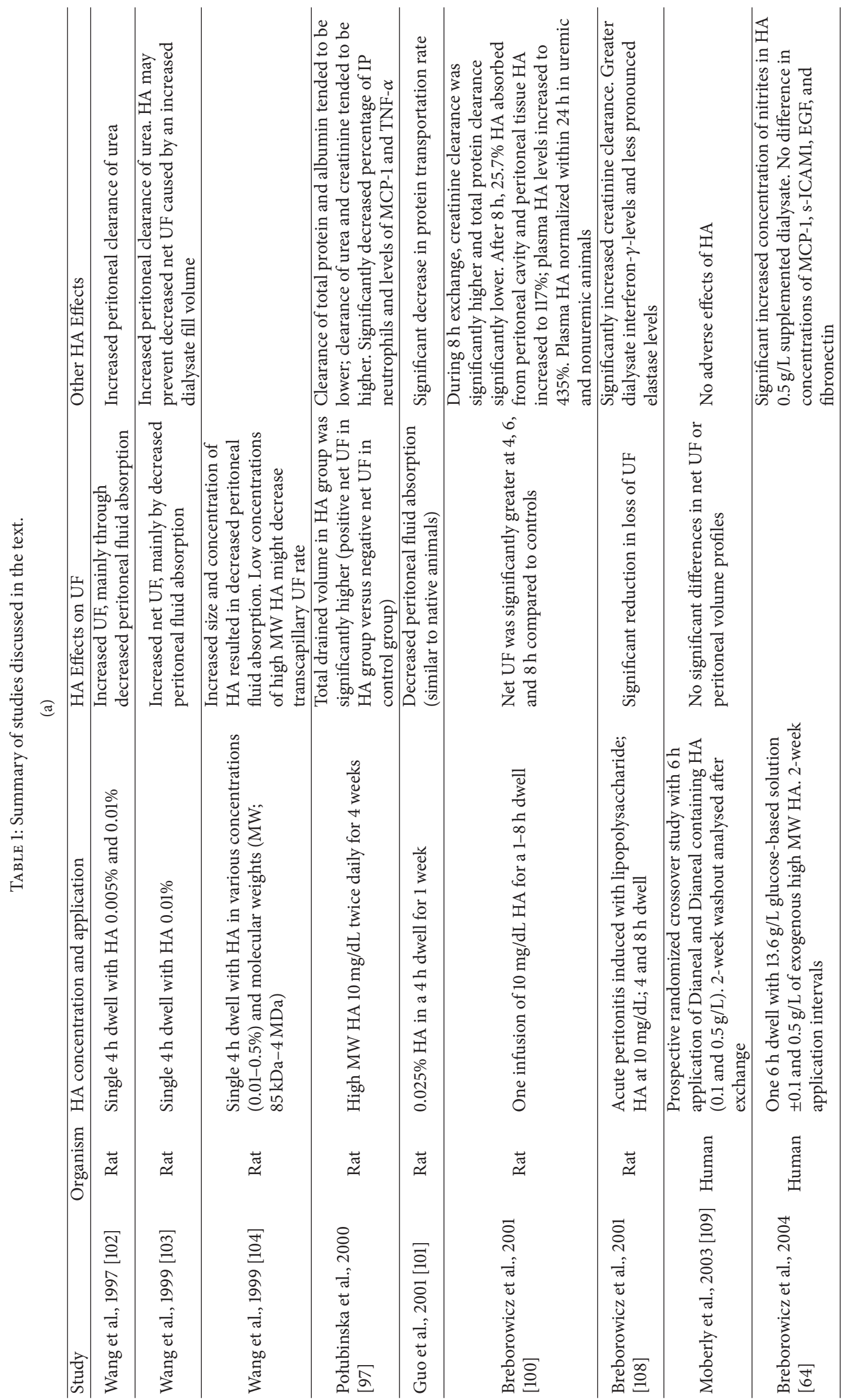




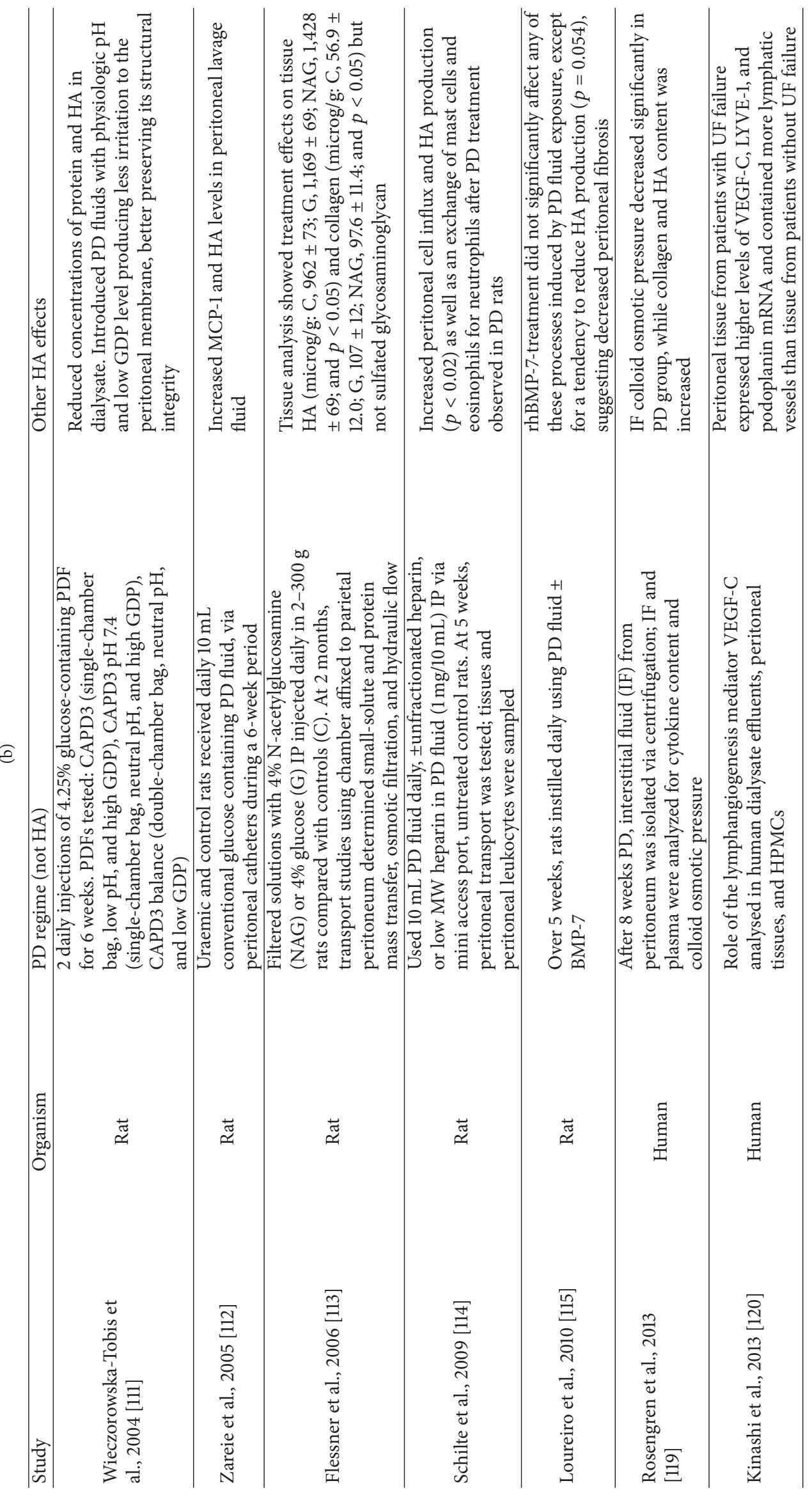


6.2. Effect of HA-Containing Fluids on Peritoneal Inflammation. The effect of HA on peritoneal inflammation has also been analysed in animal studies. IP administration of HA in rats reduced the percentage of neutrophils in PD effluent, but the total cell number in the effluent did not change [97]. This study also reported lower levels of TNF- $\alpha$ and MCP-1 in rats treated with HA-containing PD solution in comparison to rats treated with Dianeal [97]. In a model of lipopolysaccharide-induced peritonitis in rats, $10 \mathrm{mg} / \mathrm{dL} \mathrm{HA}$ administration reduced loss of UF and provided a greater creatinine clearance [108]. Furthermore, the presence of HA led to increased dialysate interferon $-\gamma$ levels, whereas elastase levels decreased [108].

6.3. HA Absorption and Metabolism after IP Application. Breborowicz and coworkers have investigated the absorption and metabolism of $10 \mathrm{mg} / \mathrm{dL}$ HA in Dianeal after IP administration [100]. After 8 hours, one quarter of the HA had been absorbed from the peritoneal cavity and peritoneal tissue, and plasma HA concentrations were significantly increased to $116 \%$ in peritoneal tissue and $435 \%$ in plasma [100]. HA levels returned to normal within 24 hours after IP administration in both healthy and uremic rats [100].

6.4. Histological Evaluation of the Peritoneal Membrane after HA Application. Only one study has provided histological evaluation of the peritoneal membrane following HA administration, showing a similar increase in the thickness of the peritoneal interstitium in rats exposed to HA and in control animals [97].

\section{HA Supplementation in Human PD}

Moberly et al. [109] examined 13 patients in a prospective randomized crossover study. The PD solutions investigated were Dianeal alone or supplemented with either $0.1 \mathrm{~g} / \mathrm{L} \mathrm{HA}$ or $0.5 \mathrm{~g} / \mathrm{L}$ HA. Each 6-hour dialysis exchange was separated from the other exchanges by a 2 -week washout period. The authors did not report any adverse events related to HA administration. HA application did not result in significant changes in net UF or peritoneal volume profiles, but mean net UF tended to be slightly higher during treatment with HAcontaining fluid. Peritoneal fluid reabsorption also tended to be lower during the HA treatment, but the differences were not significant. Solute clearances, dialysate/plasma ratios, and mass transfer area coefficients for sodium, urea, creatinine, albumin, and glucose were similar for the three treatment solutions [109]. While these data failed to reach significance, only 10 patients completed the study. In addition, HA concentrations exceeding $0.5 \mathrm{~g} / \mathrm{L}$ were not used due to increased viscosity resulting in significantly increased filling and drainage times [109]. It remains possible that a longer application period than one test solution every 2 weeks might have been more effective.

A recent review by Cho and colleagues of randomized control trials and quasirandomised control trials in adults and children compared the effects of biocompatible PD solutions [110]. These authors concluded, on the basis of what they referred to as "generally suboptimal quality evidence," that the use of neutral $\mathrm{pH}$, low glucose degradation product (GDP) solutions led to greater UF and renal preservation without statistically significant effects of peritonitis, technique failure, or patient survival [110].

7.1. HA as a Biomarker of Inflammation in PD. In more recent work on rat models and in PD patients, HA has been used as a biomarker to monitor PD progress.

Wieczorowska-Tobis and colleagues showed reduced HA concentration in dialysate from neutral $\mathrm{pH}$ and low GDP PD solutions when compared with conventional solutions in rats [111], while a study on uremic rats reported increased HA and MCP-1 in peritoneal lavage fluid [112]. A rise in the parietal peritoneal concentrations of HA and collagen followed the use of PD solutions containing $\mathrm{N}$-acetylglucosamine or glucose [113]. Increased peritoneal cell influx and HA synthesis, together with increased neutrophil counts and decreased mast cell/eosinophil numbers, were observed in rats following $\mathrm{PD}$, and these affects were not changed by the presence of unfractionated or low molecular weight heparin [114]. Reduced HA production was reported in a rat model using bone morphogenetic protein-7 (BMP-7) over a 5-week period, suggesting decreased fibrosis [115]. Use of icodextrin in PD solutions resulted in increased patient dialysate HA compared to glucose/lactate solution, suggesting increased subclinical inflammation [116].

Breborowicz et al. [64] examined the effect of Dianeal alone or Dianeal with HA supplementation of 0.1 or $0.5 \mathrm{~g} / \mathrm{L}$. Exchanges at 6 hours were performed with each of the fluids randomly at 2-week intervals. Patient dialysate nitrite concentration (as an index of NO production) was significantly higher after dialysis exchange performed with HA $0.5 \mathrm{~g} / \mathrm{L}$, but concentrations of MCP-1, s-ICAM 1, VEGF, and fibronectin were similar after exchanges with the HA-supplemented dialysate fluids and did not differ from Dianeal alone. When cultured HPMCs were exposed for 24 hours to these dialysates, the HA-containing fluids inhibited the synthesis of MCP-1, sICAM, VEGF, and fibronectin, accelerating the growth rate of proliferating cells [64].

Use of icodextrin or amino acid-based PD solutions did not result in significant changes in HA production in human dialysates [117], whereas upregulated HA synthesis was reported in whole peritoneal samples from long-term PD patients [118]. Recent reports have shown increased HA after 8 weeks of PD [119] and upregulated expression of endothelial HA receptor-1 (LYVE-1) in human dialysate effluents, peritoneal tissues, and HPMCs [120]. Most recently, Yung and colleagues analysed data from a comprehensive panel of fibrotic and inflammatory biomarkers, including HA, in a randomised prospective study of $80 \mathrm{PD}$ patients [121]. This study compared a low-glucose treatment protocol of Physioneal, Extraneal, and Nutrineal with a control group treated with Dianeal; the biomarker data suggested better preservation of membrane integrity in the multitreatment group [121].

\section{Summary}

The roles of HA in peritoneal biology, fibrosis, and dialysis require further investigation. A more complete understanding of the regulation of peritoneal HAS expression and HA 
synthesis, and of peritoneal and mesothelial responses to exogenous HA, has the potential to provide new tools with which PD treatment and prevention of surgical adhesions are improved. The manipulation of HAS expression and HA metabolism via long noncoding RNAs such as HAS2AS1 and/or microRNAs, together with recent advances in molecular analysis techniques, hold much promise in these contexts [50-52, 122-128].

\section{Disclaimer}

The views expressed in this paper are those of the authors and not necessarily those of the NHS, the NIHR, or the Department of Health, UK.

\section{Conflict of Interests}

The authors declare that there is no conflict of interests regarding the publication of this paper.

\section{Acknowledgments}

Timothy Bowen thanks Soma Meran, Aled P. Williams, and Lucy J. Newbury for their help in preparing this review, as well as Thomas Sitter (HPMC in vitro section) and Matthias Sauter (in vivo analysis section) for their contributions. The Wales Kidney Research Unit is funded by Health and Care Research Wales. The authors also acknowledge support from Kidney Research UK Project Grant Award RP44/2014 to Timothy Bowen and a Medical Research Council Clinician Scientist Award to Soma Meran. This is a publication of independent research funded by the National Institute for Health Research (NIHR) Invention for Innovation (i4i) Programme (Grant Reference no. II-LA-0712-20003). Principal Investigator for the grant is Timothy Bowen.

\section{References}

[1] K. Meyer and J. W. Palmer, "The polysaccharide of the vitreous humor," The Journal of Biological Chemistry, vol. 107, no. 3, pp. 629-634, 1934.

[2] B. Weissmann and K. Meyer, "The structure of hyalobiuronic acid and of hyaluronic acid from umbilical cord," Journal of the American Chemical Society, vol. 76, no. 7, pp. 1753-1757, 1954.

[3] P. H. Weigel, V. C. Hascall, and M. Tammi, "Hyaluronan synthases," The Journal of Biological Chemistry, vol. 272, no. 22, pp. 13997-14000, 1997.

[4] B. P. Toole, "Hyaluronan is not just a goo!," Journal of Clinical Investigation, vol. 106, no. 3, pp. 335-336, 2000.

[5] J. Y. Lee and A. P. Spicer, "Hyaluronan: A multifunctional, megaDalton, stealth molecule," Current Opinion in Cell Biology, vol. 12, no. 5, pp. 581-586, 2000.

[6] V. C. Hascall, A. K. Majors, C. A. De La Motte et al., "Intracellular hyaluronan: a new frontier for inflammation?" Biochimica et Biophysica Acta, vol. 1673, no. 1-2, pp. 3-12, 2004.

[7] A. P. Spicer and J. Y. L. Tien, "Hyaluronan and Morphogenesis," Birth Defects Research Part C-Embryo Today, vol. 72, no. 1, pp. 89-108, 2004.
[8] J. Y. L. Tien and A. P. Spicer, “Three vertebrate hyaluronan synthases are expressed during mouse development in distinct spatial and temporal patterns," Developmental Dynamics, vol. 233, no. 1, pp. 130-141, 2005.

[9] A. Moustakas and P. Heldin, "TGFbeta and matrix-regulated epithelial to mesenchymal transition," Biochimica et Biophysica Acta-General Subjects, vol. 1840, no. 8, pp. 2621-2634, 2014.

[10] P. Moffatt, E. R. Lee, B. St-Jacques, K. Matsumoto, Y. Yamaguchi, and P. J. Roughley, "Hyaluronan production by means of Has2 gene expression in chondrocytes is essential for long bone development," Developmental Dynamics, vol. 240, no. 2, pp. 404-412, 2011.

[11] B. P. Toole, "Hyaluronan: from extracellular glue to pericellular cue," Nature Reviews Cancer, vol. 4, no. 7, pp. 528-539, 2004.

[12] R. P. Wüthrich, "The proinflammatory role of hyaluronanCD44 interactions in renal injury," Nephrology Dialysis Transplantation, vol. 14, no. 11, pp. 2554-2556, 1999.

[13] S. Jones, S. Jones, and A. O. Phillips, "Regulation of renal proximal tubular epithelial cell hyaluronan generation: implications for diabetic nephropathy," Kidney International, vol. 59, no. 5, pp. 1739-1749, 2001.

[14] C. M. Milner and A. J. Day, "TSG-6: a multifunctional protein associated with inflammation," Journal of Cell Science, vol. 116, part 10, pp. 1863-1873, 2003.

[15] Y. Nishida, C. B. Knudson, and W. Knudson, "Osteogenic protein-1 inhibits matrix depletion in a hyaluronan hexasaccharide-induced model of osteoarthritis," Osteoarthritis and Cartilage, vol. 12, no. 5, pp. 374-382, 2004.

[16] T. S. Wilkinson, S. Potter-Perigo, C. Tsoi, L. C. Altman, and T. N. Wight, "Pro- and anti-inflammatory factors cooperate to control hyaluronan synthesis in lung fibroblasts," American Journal of Respiratory Cell and Molecular Biology, vol. 31, no. 1, pp. 92-99, 2004.

[17] T. S. Wilkinson, S. L. Bressler, S. P. Evanko, K. R. Braun, and T. N. Wight, "Overexpression of hyaluronan synthases alters vascular smooth muscle cell phenotype and promotes monocyte adhesion," Journal of Cellular Physiology, vol. 206, no. 2, pp. 378-385, 2006.

[18] L. Zhuo, V. C. Hascall, and K. Kimata, "Inter- $\alpha$-trypsin inhibitor, a covalent protein-glycosaminoglycan-protein complex," The Journal of Biological Chemistry, vol. 279, no. 37, pp. 38079-38082, 2004.

[19] A. Zoltan-Jones, L. Huang, S. Ghatak, and B. P. Toole, "Elevated hyaluronan production induces mesenchymal and transformed properties in epithelial cells," The Journal of Biological Chemistry, vol. 278, no. 46, pp. 45801-45810, 2003.

[20] M. E. Mummert, "Immunologic roles of hyaluronan," Immunologic Research, vol. 31, no. 3, pp. 189-205, 2005.

[21] S. Misra, V. C. Hascall, R. R. Markwald, and S. Ghatak, "Interactions between hyaluronan and its receptors (CD44, RHAMM) regulate the activities of inflammation and cancer," Frontiers in Immunology, vol. 6, article 201, 2015.

[22] M. Rienks, A.-P. Papageorgiou, N. G. Frangogiannis, and S. Heymans, "Myocardial extracellular matrix: an ever-changing and diverse entity," Circulation Research, vol. 114, no. 5, pp. 872$888,2014$.

[23] S. Yung, K. F. Cheung, Q. Zhang, and T. M. Chan, "Mediators of inflammation and their effect on resident renal cells: implications in lupus nephritis," Clinical and Developmental Immunology, vol. 2013, Article ID 317682, 10 pages, 2013. 
[24] A. Migliore and S. Procopio, "Effectiveness and utility of hyaluronic acid in osteoarthritis," Clinical Cases in Mineral and Bone Metabolism, vol. 12, no. 1, pp. 31-33, 2015.

[25] D. F. Remst, E. N. Blaney Davidson, and P. M. van der Kraan, "Unravelling osteoarthritis-related synovial fibrosis: a step closer to solving joint stiffness," Rheumatology, 2015.

[26] A. C. Midgley, L. Duggal, R. Jenkins et al., "Hyaluronan regulates bone morphogenetic protein-7-dependent prevention and reversal of myofibroblast phenotype," The Journal of Biological Chemistry, vol. 290, no. 18, pp. 11218-11234, 2015.

[27] S. Meran and R. Steadman, "Fibroblasts and myofibroblasts in renal fibrosis," International Journal of Experimental Pathology, vol. 92, no. 3, pp. 158-167, 2011.

[28] A. Wang, J. Ren, C. P. Wang, and V. C. Hascall, "Heparin prevents intracellular hyaluronan synthesis and autophagy responses in hyperglycemic dividing mesangial cells and activates synthesis of an extensive extracellular monocyte-adhesive hyaluronan matrix after completing cell division," Journal of Biological Chemistry, vol. 289, no. 13, pp. 9418-9429, 2014.

[29] L. Zhang, T. Bowen, F. Grennan-Jones et al., "Thyrotropin receptor activation increases hyaluronan production in preadipocyte fibroblasts," Journal of Biological Chemistry, vol. 284, no. 39, pp. 26447-26455, 2009.

[30] T. Bowen, R. H. Jenkins, and D. J. Fraser, "MicroRNAs, transforming growth factor beta-1, and tissue fibrosis," Journal of Pathology, vol. 229, no. 2, pp. 274-285, 2013.

[31] J. D. Williams, N. Topley, K. J. Craig et al., "The Euro-Balance Trial: the effect of a new biocompatible peritoneal dialysis fluid (balance) on the peritoneal membrane," Kidney International, vol. 66, no. 1, pp. 408-418, 2004.

[32] S. Yung and T. M. Chan, "Pathophysiology of the peritoneal membrane during peritoneal dialysis: the role of hyaluronan," Journal of Biomedicine and Biotechnology, vol. 2011, Article ID 180594, 11 pages, 2011.

[33] S. Yung, G. J. Thomas, and M. Davies, "Induction of hyaluronan metabolism after mechanical injury of human peritoneal mesothelial cells in vitro," Kidney International, vol. 58, no. 5, pp. 1953-1962, 2000.

[34] J. A. Mack, S. R. Abramson, Y. Ben et al., "Hoxb13 knockout adult skin exhibits high levels of hyaluronan and enhanced wound healing," The FASEB Journal, vol. 17, no. 10, pp. 13521354, 2003.

[35] Y. Yamada, N. Itano, K.-I. Hata, M. Ueda, and K. Kimata, "Differential regulation by IL-1beta; and EGF of expression of three different hyaluronan synthases in oral mucosal epithelial cells and fibroblasts and dermal fibroblasts: quantitative analysis using real-time RT-PCR," Journal of Investigative Dermatology, vol. 122, no. 3, pp. 631-639, 2004.

[36] R. Tammi, S. Pasonen-Seppänen, E. Kolehmainen, and M. Tammi, "Hyaluronan synthase induction and hyaluronan accumulation in mouse epidermis following skin injury," Journal of Investigative Dermatology, vol. 124, no. 5, pp. 898-905, 2005.

[37] A. C. Midgley, M. Rogers, M. B. Hallett et al., "Transforming growth factor- $\beta 1$ (TGF- $\beta 1$ )-stimulated fibroblast to myofibroblast differentiation is mediated by hyaluronan (HA)-facilitated epidermal growth factor receptor (EGFR) and CD44 colocalization in lipid rafts," Journal of Biological Chemistry, vol. 288, no. 21, pp. 14824-14838, 2013.

[38] K. L. Aya and R. Stern, "Hyaluronan in wound healing: rediscovering a major player," Wound Repair and Regeneration, vol. 22, no. 5, pp. 579-593, 2014.
[39] R. M. L. Simpson, S. Meran, D. Thomas et al., "Age-related changes in pericellular hyaluronan organization leads to impaired dermal fibroblast to myofibroblast differentiation," The American Journal of Pathology, vol. 175, no. 5, pp. 1915-1928, 2009.

[40] A. P. Spicer, M. F. Seldin, A. S. Olsen et al., "Chromosomal localization of the human and mouse hyaluronan synthase genes," Genomics, vol. 41, no. 3, pp. 493-497, 1997.

[41] S. Yung, G. A. Coles, and M. Davies, "IL-1 beta, a major stimulator of hyaluronan synthesis in vitro of human peritoneal mesothelial cells: relevance to peritonitis in CAPD," Kidney International, vol. 50, no. 4, pp. 1337-1343, 1996.

[42] S. Yung and M. Davies, "Response of the human peritoneal mesothelial cell to injury: an in vitro model of peritoneal wound healing," Kidney International, vol. 54, no. 6, pp. 2160-2169, 1998.

[43] J. Monslow, J. D. Williams, N. Norton et al., "The human hyaluronan synthase genes: genomic structures, proximal promoters and polymorphic microsatellite markers," International Journal of Biochemistry and Cell Biology, vol. 35, no. 8, pp. 1272$1283,2003$.

[44] B. Hoogendoorn, S. L. Coleman, C. A. Guy et al., "Functional analysis of human promoter polymorphisms," Human Molecular Genetics, vol. 12, no. 18, pp. 2249-2254, 2003.

[45] J. Monslow, J. D. Williams, C. A. Guy et al., "Identification and analysis of the promoter region of the human hyaluronan synthase 2 gene," The Journal of Biological Chemistry, vol. 279, no. 20, pp. 20576-20581, 2004.

[46] A. C. Midgley and T. Bowen, "Analysis of human hyaluronan synthase gene transcriptional regulation and downstream hyaluronan cell surface receptor mobility in myofibroblast differentiation," Methods in Molecular Biology, vol. 1229, pp. 605618, 2015.

[47] S. Wang, L. Zhen, Z. Liu et al., "Identification and analysis of the promoter region of the human HAS3 gene," Biochemical and Biophysical Research Communications, vol. 460, no. 4, pp. 10081014, 2015.

[48] J. Monslow, J. D. Williams, D. J. Fraser et al., "Sp1 and Sp3 mediate constitutive transcription of the human hyaluronan synthase 2 gene," Journal of Biological Chemistry, vol. 281, no. 26, pp. 18043-18050, 2006.

[49] K. Saavalainen, M. I. Tammi, T. Bowen, M. L. Schmitz, and C. Carlberg, "Integration of the activation of the human hyaluronan synthase 2 gene promoter by common cofactors of the transcription factors retinoic acid receptor and nuclear factor $\kappa \mathrm{B}$," The Journal of Biological Chemistry, vol. 282, no. 15, pp. 11530-11539, 2007.

[50] H. Chao and A. P. Spicer, "Natural antisense mRNAs to hyaluronan synthase 2 inhibit hyaluronan biosynthesis and cell proliferation," Journal of Biological Chemistry, vol. 280, no. 30, pp. 27513-27522, 2005.

[51] D. R. Michael, A. O. Phillips, A. Krupa et al., "The human hyaluronan synthase 2 (HAS2) gene and its natural antisense RNA exhibit coordinated expression in the renal proximal tubular epithelial cell," Journal of Biological Chemistry, vol. 286, no. 22, pp. 19523-19532, 2011.

[52] D. Vigetti, S. Deleonibus, P. Moretto et al., "Natural antisense transcript for hyaluronan synthase 2 (HAS2-AS1) induces transcription of HAS2 via protein O-GlcNAcylation," The Journal of Biological Chemistry, vol. 289, no. 42, pp. 28816-28826, 2014.

[53] L. Chen, R. D. Neville, D. R. Michael et al., "Identification and analysis of the human hyaluronan synthase 1 gene promoter 
reveals Smad3- and Sp3-mediated transcriptional induction," Matrix Biology, vol. 31, no. 7-8, pp. 373-379, 2012.

[54] S. Yung, G. A. Coles, J. D. Williams, and M. Davies, "The source and possible significance of hyaluronan in the peritoneal cavity," Kidney International, vol. 46, no. 2, pp. 527-533, 1994.

[55] A. Breborowicz, J. Wisniewska, A. Polubinska, K. Wieczorowska-Tobis, L. Martis, and D. G. Oreopoulos, "Role of Peritoneal Mesothelial cells and fibroblasts in the synthesis of hyaluronan during peritoneal dialysis," Peritoneal Dialysis International, vol. 18, no. 4, pp. 382-386, 1998.

[56] K. N. Lai, C. C. Szeto, K. B. Lai, C. W. K. Lam, D. T. M. Chan, and J. C. K. Leung, "Increased production of hyaluronan by peritoneal cells and its significance in patients on CAPD," American Journal of Kidney Diseases, vol. 33, no. 2, pp. 318-324, 1999.

[57] A. Honda, Y. Sekiguchi, and Y. Mori, "Prostaglandin E2 stimulates cyclic AMP-mediated hyaluronan synthesis in rabbit pericardial mesothelial cells," Biochemical Journal, vol. 292, no. 2, pp. 497-502, 1993.

[58] B. P. Toole, "Hyaluronan and its binding proteins, the hyaladherins," Current Opinion in Cell Biology, vol. 2, no. 5, pp. 839844, 1990.

[59] L. Sherman, J. Sleeman, P. Herrlich, and H. Ponta, "Hyaluronate receptors: key players in growth, differentiation, migration and tumor progression," Current Opinion in Cell Biology, vol. 6, no. 5, pp. 726-733, 1994.

[60] R. Stern and M. J. Jedrzejas, "Hyaluronidases: their genomics, structures, and mechanisms of action," Chemical Reviews, vol. 106, no. 3, pp. 818-839, 2006.

[61] U. B. G. Laurent, J. R. E. Fraser, A. Engstrom-Laurent, R. K. Reed, L. B. Dahl, and T. C. Laurent, "Catabolism of hyaluronan in the knee joint of the rabbit," Matrix, vol. 12, no. 2, pp. 130-136, 1992.

[62] M. M. P. J. Reijnen, P. Falk, H. van Goor, and L. Holmdahl, “The antiadhesive agent sodium hyaluronate increases the proliferation rate of human peritoneal mesothelial cells," Fertility and Sterility, vol. 74, no. 1, pp. 146-151, 2000.

[63] T. Horiuchi, K. Miyamoto, S. Miyamoto et al., "Image analysis of remesothelialization following chemical wounding of cultured human peritoneal mesothelial cells: the role of hyaluronan synthesis," Kidney International, vol. 64, no. 6, pp. 2280-2290, 2003.

[64] A. Breborowicz, M. Pyda, J. Moberly, L. Martis, and D. Oreopoulos, "Effect of haluronan-supplemented dialysate on in vitro function of human peritoneal mesothelial cells," American Journal of Nephrology, vol. 24, no. 3, pp. 316-321, 2004.

[65] A. Neumann, R. Schinzel, D. Palm, P. Riederer, and G. Münch, "High molecular weight hyaluronic acid inhibits advanced glycation endproduct-induced NF-kappaB activation and cytokine expression," FEBS Letters, vol. 453, no. 3, pp. 283-287, 1999.

[66] T. Sitter, M. Sauter, and B. Haslinger, "Modulation of fibrinolytic system components in mesothelial cells by hyaluronan," Peritoneal Dialysis International, vol. 23, no. 3, pp. 222-227, 2003.

[67] C. J. J. M. Sikkink, M. M. P. J. Reijnen, P. Falk, H. van Goor, and L. Holmdahl, "Influence of monocyte-like cells on the fibrinolytic activity of peritoneal mesothelial cells and the effect of sodium hyaluronate," Fertility and Sterility, vol. 84, no. 2, pp. 1072-1077, 2005.

[68] C. M. McKee, M. B. Penno, M. Cowman et al., "Hyaluronan (HA) fragments induce chemokine gene expression in alveolar macrophages. The role of HA size and CD44," The Journal of Clinical Investigation, vol. 98, no. 10, pp. 2403-2413, 1996.
[69] C. M. McKee, C. J. Lowenstein, M. R. Horton et al., "Hyaluronan fragments induce nitric-oxide synthase in murine macrophages through a nuclear factor kappaB-dependent mechanism," The Journal of Biological Chemistry, vol. 272, no. 12, pp. 8013-8018, 1997.

[70] B. Beck-Schimmer, B. Oertli, T. Pasch, and R. P. Wüthrich, "Hyaluronan induces monocyte chemoattractant protein-1 expression in renal tubular epithelial cells," Journal of the American Society of Nephrology, vol. 9, no. 12, pp. 2283-2290, 1998.

[71] B. Haslinger, S. Mandl-Weber, A. Sellmayer, and T. Sitter, "Hyaluronan fragments induce the synthesis of MCP-1 and IL-8 in cultured human peritoneal mesothelial cells," Cell and Tissue Research, vol. 305, no. 1, pp. 79-86, 2001.

[72] A. Breborowicz, M. Breborowicz, and D. G. Oreopoulos, "Glucose-induced changes in the phenotype of human peritoneal mesothelial cells: effect of L-2-oxothiazolidine carboxylic acid," American Journal of Nephrology, vol. 23, no. 6, pp. 471-476, 2003.

[73] M. Ciszewicz, G. Wu, P. Tam, A. Polubinska, and A. Bręborowicz, "Changes in peritoneal mesothelial cells phenotype after chronic exposure to glucose or $N$-acetylglucosamine," Translational Research, vol. 150, no. 6, pp. 337-342, 2007.

[74] S. K. Kavoussi, C. A. Witz, P. A. Binkley, A. S. Nair, and D. I. Lebovic, "Peroxisome-proliferator activator receptor-gamma activation decreases attachment of endometrial cells to peritoneal mesothelial cells in an in vitro model of the early endometriotic lesion," Molecular Human Reproduction, vol. 15, no. 10, pp. 687-692, 2009.

[75] M. Ciszewicz, G. Wu, P. Tam, A. Polubinska, and A. B. Borowicz, "Glucose but not $\mathrm{N}$-acetylglucosamine accelerates in vitro senescence of human peritoneal mesothelial cells," International Journal of Artificial Organs, vol. 34, no. 6, pp. 489-494, 2011.

[76] S. P. Evanko, M. I. Tammi, R. H. Tammi, and T. N. Wight, "Hyaluronan-dependent pericellular matrix," Advanced Drug Delivery Reviews, vol. 59, no. 13, pp. 1351-1365, 2007.

[77] S. Yung and T. M. Chan, "Glycosaminoglycans and proteoglycans: overlooked entities?" Peritoneal Dialysis International, vol. 27, supplement 2, pp. S104-S109, 2007.

[78] V. Koistinen, R. Kärnä, A. Koistinen, A. Arjonen, M. Tammi, and K. Rilla, "Cell protrusions induced by hyaluronan synthase 3 (HAS3) resemble mesothelial microvilli and share cytoskeletal features of filopodia," Experimental Cell Research, vol. 337, no. 2, pp. 179-191, 2015.

[79] C. B. S. Henry and B. R. Duling, "Permeation of the luminal capillary glycocalyx is determined by hyaluronan," The American Journal of Physiology-Heart and Circulatory Physiology, vol. 277, no. 2, part 2, pp. H508-H514, 1999.

[80] L. Gao and H. H. Lipowsky, "Composition of the endothelial glycocalyx and its relation to its thickness and diffusion of small solutes," Microvascular Research, vol. 80, no. 3, pp. 394-401, 2010.

[81] C. A. Vlahu, D. Lopes Barreto, D. G. Struijk, H. Vink, and R. T. Krediet, "Is the systemic microvascular endothelial glycocalyx in peritoneal dialysis patients related to peritoneal transport?" Nephron Clinical Practice, vol. 128, no. 1-2, pp. 159-165, 2014.

[82] S. Tsuji, K. Takahashi, H. Yomo et al., "Effectiveness of antiadhesion barriers in preventing adhesion after myomectomy in patients with uterine leiomyoma," European Journal of Obstetrics Gynecology and Reproductive Biology, vol. 123, no. 2, pp. 244-248, 2005.

[83] H. Roman, M. Canis, M. Kamble, R. Botchorishvili, J.-L. Pouly, and G. Mage, "Efficacy of three adhesion-preventing 
agents in reducing severe peritoneal trauma induced by bipolar coagulation in a laparoscopic rat model," Fertility and Sterility, vol. 83, no. 4, supplement, pp. 1113-1118, 2005.

[84] R. Detchev, M. Bazot, D. Soriano, and E. Darai, "Prevention of de novo adhesion by ferric hyaluronate gel after laparoscopic surgery in an animal model," Journal of the Society of Laparoendoscopic Surgeons, vol. 8, no. 3, pp. 263-268, 2004.

[85] Z. Cohen, A. J. Senagore, M. T. Dayton et al., "Prevention of postoperative abdominal adhesions by a novel, glycerol/ sodium hyaluronate/carboxymethylcellulose-based bioresorbable membrane: a prospective, randomized, evaluator-blinded multicenter study," Diseases of the Colon and Rectum, vol. 48, no. 6, pp. 1130-1139, 2005.

[86] E. Nilsson, C. Björn, V. Sjöstrand et al., "A novel polypeptide derived from human lactoferrin in sodium hyaluronate prevents postsurgical adhesion formation in the rat," Annals of Surgery, vol. 250, no. 6, pp. 1021-1028, 2009.

[87] R. Lim, J. M. Morrill, R. C. Lynch et al., "Practical limitations of bioresorbable membranes in the prevention of intra-abdominal adhesions," Journal of Gastrointestinal Surgery, vol. 13, no. 1, pp. 35-42, 2009.

[88] R. Lim, A. F. Stucchi, J. M. Morrill, K. L. Reed, R. Lynch, and J. M. Becker, "The efficacy of a hyaluronate-carboxymethylcellulose bioresorbable membrane that reduces postoperative adhesions is increased by the intra-operative co-administration of a neurokinin 1 receptor antagonist in a rat model," Surgery, vol. 148, no. 5, pp. 991-999, 2010.

[89] M. A. Lalountas, K. D. Ballas, C. Skouras et al., "Preventing intraperitoneal adhesions with atorvastatin and sodium hyaluronate/carboxymethylcellulose: a comparative study in rats," American Journal of Surgery, vol. 200, no. 1, pp. 118-123, 2010.

[90] D. Economidou, D. Kapoukranidou, C. Dimitriadis et al., "Osmotic nephrosis due to the use of anti-adhesive membrane intraperitoneally," Nephrology Dialysis Transplantation, vol. 26, no. 2, pp. 697-701, 2011.

[91] K. E. Greenawalt, M. J. Colt, R. L. Corazzini, O. L. Syrkina, and T. H. Jozefiak, "Remote efficacy for two different forms of hyaluronate-based adhesion barriers," Journal of Investigative Surgery, vol. 25, no. 3, pp. 174-180, 2012.

[92] H. J. Hwang, M. S. An, T. K. Ha et al., "All the commercially available adhesion barriers have the same effect on adhesion prophylaxis?; a comparison of barrier agents using a newly developed, severe intra-abdominal adhesion model," International Journal of Colorectal Disease, vol. 28, no. 8, pp. 1117-1125, 2013.

[93] K. Caglayan, B. Gungor, H. Cinar, N. Y. Erdogan, and B. Koca, "Preventing intraperitoneal adhesions with linezolid and hyaluronic acid/carboxymethylcellulose: a comparative study in cecal abrasion model," American Journal of Surgery, vol. 208, no. 1, pp. 106-111, 2014.

[94] E. Arslan, T. Talih, B. Oz, B. Halaclar, K. Caglayan, and M. Sipahi, "Comparison of lovastatin and hyaluronic acid/carboxymethyl cellulose on experimental created peritoneal adhesion model in rats," International Journal of Surgery, vol. 12, no. 2, pp. 120-124, 2014.

[95] A. Ohata, N. Tamura, K. Iwata et al., "Trehalose solution protects mesothelium and reduces bowel adhesions," Journal of Surgical Research, vol. 191, no. 1, pp. 224-230, 2014.

[96] S. Sakai, K. Ueda, and M. Taya, "Peritoneal adhesion prevention by a biodegradable hyaluronic acid-based hydrogel formed in situ through a cascade enzyme reaction initiated by contact with body fluid on tissue surfaces," Acta Biomaterialia, vol. 24, pp. 152-158, 2015.

[97] A. Połubinska, K. Pawlaczyk, M. Kuzlan-Pawlaczyk et al., "Dialysis solution containing hyaluronan: effect on peritoneal permeability and inflammation in rats," Kidney International, vol. 57, no. 3, pp. 1182-1189, 2000.

[98] G. W. Lipkin, M. A. Forbes, E. H. Cooper, and J. H. Turney, "Hyaluronic acid metabolism and its clinical significance in patients treated by continuous ambulatory peritoneal dialysis," Nephrology Dialysis Transplantation, vol. 8, no. 4, pp. 357-360, 1993.

[99] K. Yamagata, C. Tomida, and A. Koyama, "Intraperitoneal hyaluronan production in stable continuous ambulatory peritoneal dialysis patients," Peritoneal Dialysis International, vol. 19, no. 2, pp. 131-137, 1999.

[100] A. Breborowicz, A. Polubinska, K. Pawlaczyk et al., "Intraperitoneal hyaluronan administration in conscious rats: absorption, metabolism, and effects on peritoneal fluid dynamics," Peritoneal Dialysis International, vol. 21, no. 2, pp. 130-135, 2001.

[101] Q.-Y. Guo, W.-X. Peng, H.-H. Cheng, R.-G. Ye, B. Lindholm, and T. Wang, "Hyaluronan preserves peritoneal membrane transport properties," Peritoneal Dialysis International, vol. 21, no. 2, pp. 136-142, 2001.

[102] T. Wang, C. Chen, O. Heimbürger, J. Waniewski, J. Bergström, and B. Lindholm, "Hyaluronan decreases peritoneal fluid absorption in peritoneal dialysis," Journal of the American Society of Nephrology, vol. 8, no. 12, pp. 1915-1920, 1997.

[103] T. Wang, H.-H. Cheng, O. Heimbürger et al., "Intraperitoneal addition of hyaluronan improves peritoneal dialysis efficiency," Peritoneal Dialysis International, vol. 19, supplement 2, pp. S106S111, 1999.

[104] T. Wang, H.-H. Cheng, O. Heimbürger et al., "Hyaluronan decreases peritoneal fluid absorption: effect of molecular weight and concentration of hyaluronan," Kidney International, vol. 55, no. 2, pp. 667-673, 1999.

[105] T. Wang, H.-H. Cheng, O. Heimbürger, J. Waniewski, J. Bergström, and B. Lindholm, "Hyaluronan prevents the decreased net ultrafiltration caused by increased peritoneal dialysate fill volume," Kidney International, vol. 53, no. 2, pp. 496-502, 1998.

[106] B.-I. Rosengren, O. Carlsson, and B. Rippe, "Hyaluronan and peritoneal ultrafiltration: a test of the "filter-cake" hypothesis," American Journal of Kidney Diseases, vol. 37, no. 6, pp. 12771285, 2001.

[107] O. Carlsson, B.-I. Rosengren, and B. Rippe, "Effects of peritoneal hyaluronidase treatment on transperitoneal solute and fluid transport in the rat," Acta Physiologica Scandinavica, vol. 168, no. 3, pp. 371-376, 2000.

[108] A. Breborowicz, A. Polubinska, J. Moberly, K. Ogle, L. Martis, and D. Oreopoulos, "Hyaluronan modifies inflammatory response and peritoneal permeability during peritonitis in rats," American Journal of Kidney Diseases, vol. 37, no. 3, pp. 594-600, 2001.

[109] J. B. Moberly, M. Sorkin, A. Kucharski et al., "Effects of intraperitoneal hyaluronan on peritoneal fluid and solute transport in peritoneal dialysis patients," Peritoneal Dialysis International, vol. 23, no. 1, pp. 63-73, 2003.

[110] Y. Cho, D. W. Johnson, J. C. Craig, G. F. M. Strippoli, S. V. Badve, and K. J. Wiggins, "Biocompatible dialysis fluids for peritoneal dialysis," Cochrane Database of Systematic Reviews, vol. 3, Article ID CD007554, 2014.

[111] K. Wieczorowska-Tobis, R. Brelinska, J. Witowski et al., "Evidence for less irritation to the peritoneal membrane in rats 
dialyzed with solutions low in glucose degradation products," Peritoneal Dialysis International, vol. 24, no. 1, pp. 48-57, 2004.

[112] M. Zareie, A. S. De Vriese, L. H. P. Hekking et al., "Immunopathological changes in a uraemic rat model for peritoneal dialysis," Nephrology Dialysis Transplantation, vol. 20, no. 7, pp. 1350-1361, 2005.

[113] M. F. Flessner, J. Choi, H. Vanpelt et al., "Correlating structure with solute and water transport in a chronic model of peritoneal inflammation," American Journal of Physiology -Renal Physiology, vol. 290, no. 1, pp. F232-F240, 2006.

[114] M. N. Schilte, J. Loureiro, E. D. Keuming et al., "Long-term intervention with heparins in a rat model of peritoneal dialysis," Peritoneal Dialysis International, vol. 29, no. 1, pp. 26-35, 2009.

[115] J. Loureiro, M. Schilte, A. Aguilera et al., "BMP-7 blocks mesenchymal conversion of mesothelial cells and prevents peritoneal damage induced by dialysis fluid exposure," Nephrology Dialysis Transplantation, vol. 25, no. 4, pp. 1098-1108, 2010.

[116] A. Parikova, M. M. Zweers, D. G. Struijk, and R. T. Krediet, "Peritoneal effluent markers of inflammation in patients treated with icodextrin-based and glucose-based dialysis solutions," Advances in Peritoneal Dialysis, vol. 19, pp. 186-190, 2003.

[117] T. A. Martikainen, A.-M. Teppo, C. Grönhagen-Riska, and A. V. Ekstrand, "Glucose-free dialysis solutions: inductors of inflammation or preservers of peritoneal membrane?" Peritoneal Dialysis International, vol. 25, no. 5, pp. 453-460, 2005.

[118] S. Osada, C. Hamada, T. Shimaoka, K. Kaneko, S. Horikoshi, and Y. Tomino, "Alterations in proteoglycan components and histopathology of the peritoneum in uraemic and peritoneal dialysis (PD) patients," Nephrology Dialysis Transplantation, vol. 24, no. 11, pp. 3504-3512, 2009.

[119] B.-I. Rosengren, S. J. Sagstad, T. V. Karlsen, and H. Wiig, "Isolation of interstitial fluid and demonstration of local proinflammatory cytokine production and increased absorptive gradient in chronic peritoneal dialysis," American Journal of PhysiologyRenal Physiology, vol. 304, no. 2, pp. F198-F206, 2013.

[120] H. Kinashi, Y. Ito, M. Mizuno et al., "TGF- $\beta 1$ promotes lymphangiogenesis during peritoneal fibrosis," Journal of the American Society of Nephrology, vol. 24, no. 10, pp. 1627-1642, 2013.

[121] S. Yung, S. L. Lui, C. K. Ng et al., "Impact of a low-glucose peritoneal dialysis regimen on fibrosis and inflammation biomarkers," Peritoneal Dialysis International, vol. 35, no. 2, pp. 147-158, 2015.

[122] A. C. Midgley, T. Bowen, A. O. Phillips, and R. Steadman, "MicroRNA-7 inhibition rescues age-associated loss of epidermal growth factor receptor and hyaluronan-dependent differentiation in fibroblasts," Aging Cell, vol. 13, no. 2, pp. 235-244, 2014.

[123] K. Röck, J. Tigges, S. Sass et al., "miR-23a-3p causes cellular senescence by targeting hyaluronan synthase 2: possible implication for skin aging," Journal of Investigative Dermatology, vol. 135, no. 2, pp. 369-377, 2015.

[124] T. Bowen, “A role for fibrocytes in peritoneal fibrosis?" Peritoneal Dialysis International, vol. 32, no. 1, pp. 4-6, 2012.

[125] C. Beltrami, A. Clayton, A. O. Phillips, D. J. Fraser, and T. Bowen, "Analysis of urinary microRNAs in chronic kidney disease," Biochemical Society Transactions, vol. 40, no. 4, pp. 875879, 2012.

[126] J. Martin, R. H. Jenkins, R. Bennagi et al., "Post-transcriptional regulation of transforming growth factor $\beta-1$ by microRNA744," PLoS ONE, vol. 6, no. 10, Article ID e25044, 2011.
[127] R. H. Jenkins, J. Martin, A. O. Phillips, T. Bowen, and D. J. Fraser, "Transforming growth factor $\beta 1$ represses proximal tubular cell microRNA-192 expression through decreased hepatocyte nuclear factor DNA binding," Biochemical Journal, vol. 443, no. 2, pp. 407-416, 2012.

[128] R. H. Jenkins, L. C. Davies, P. R. Taylor et al., "MiR-192 induces G2/M growth arrest in aristolochic acid nephropathy," The American Journal of Pathology, vol. 184, no. 4, pp. 996-1009, 2014. 


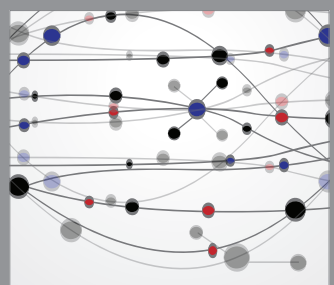

The Scientific World Journal
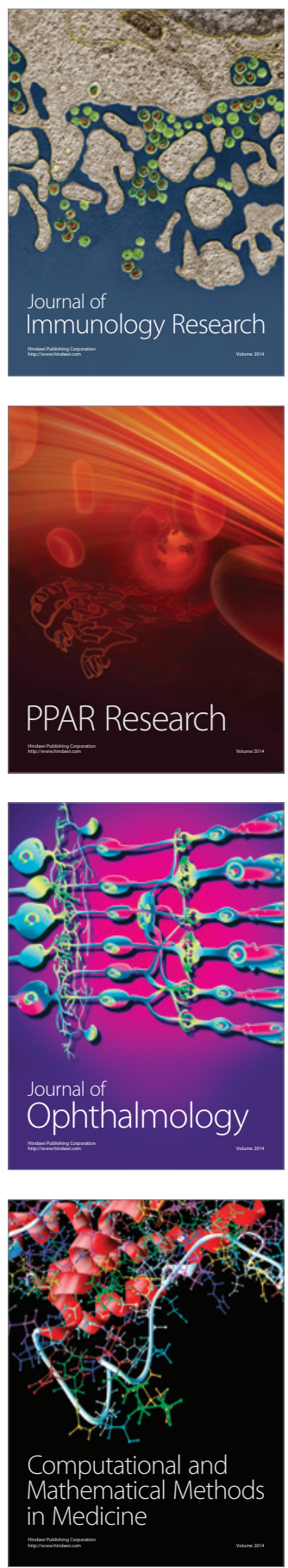

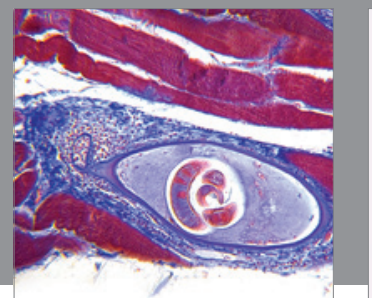

Gastroenterology

Research and Practice
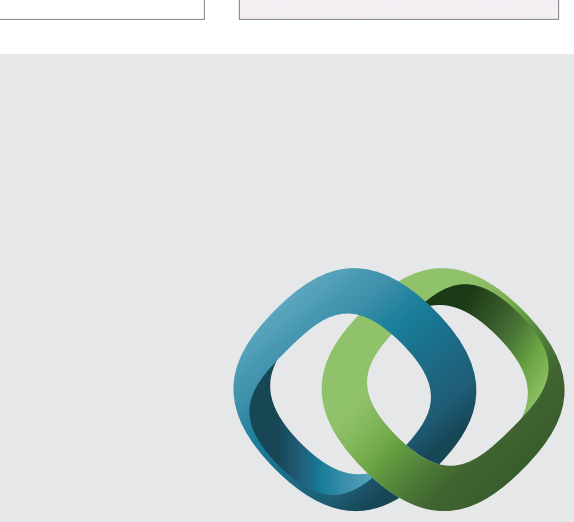

\section{Hindawi}

Submit your manuscripts at

http://www.hindawi.com
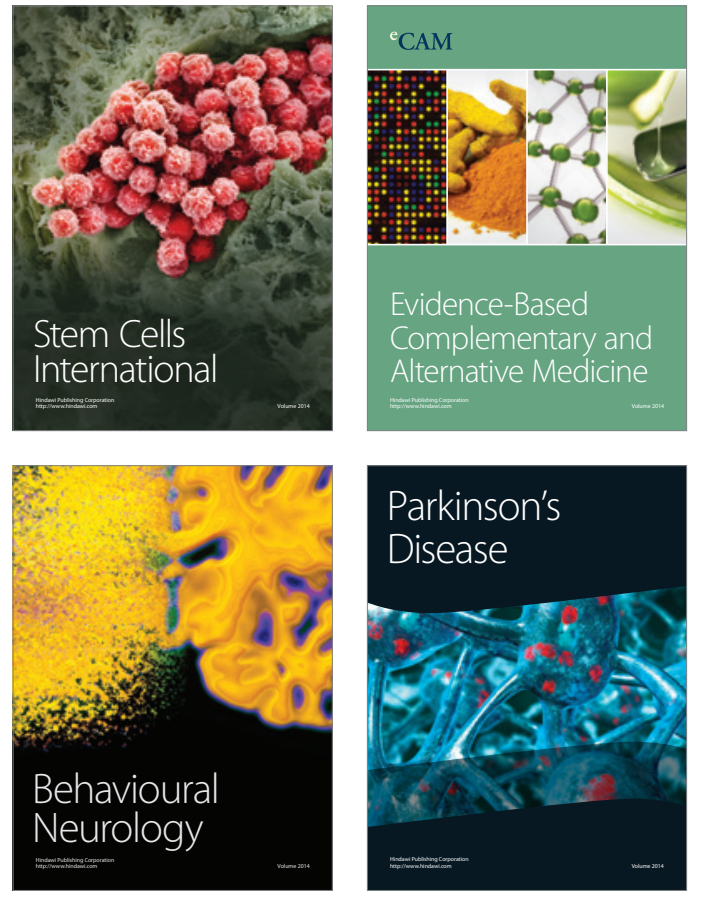
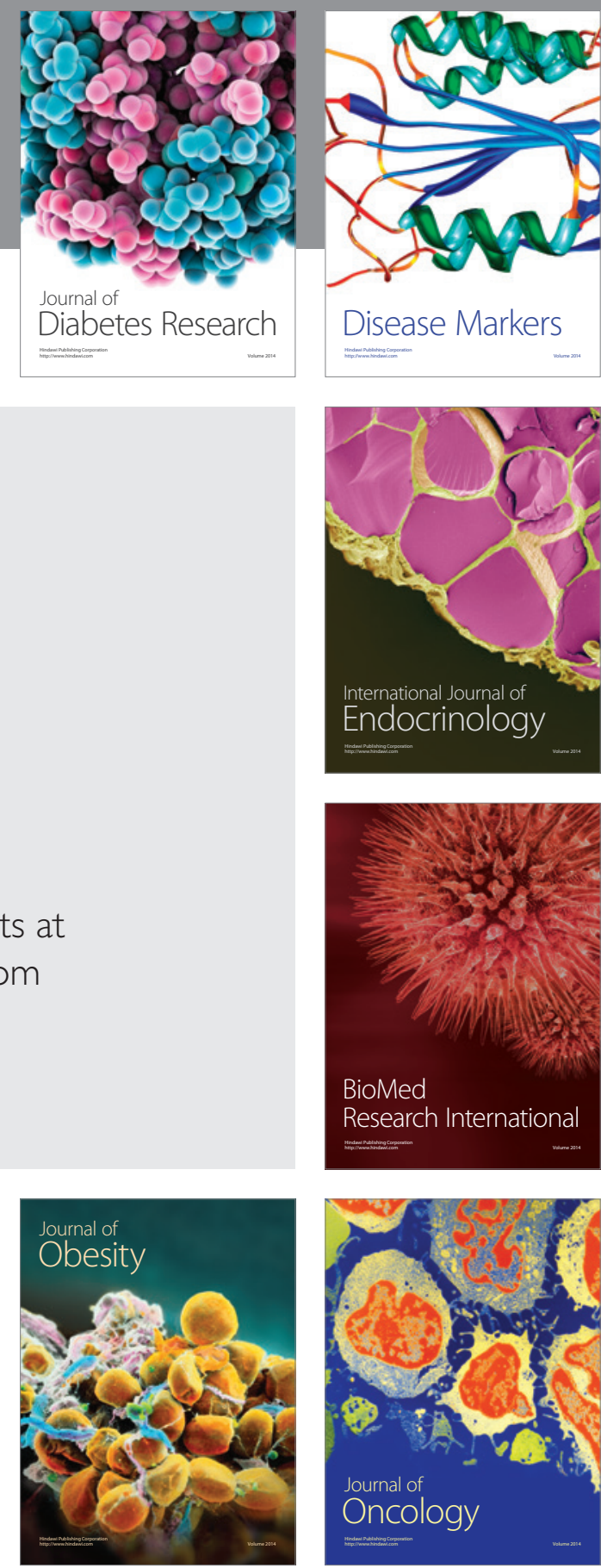

Disease Markers
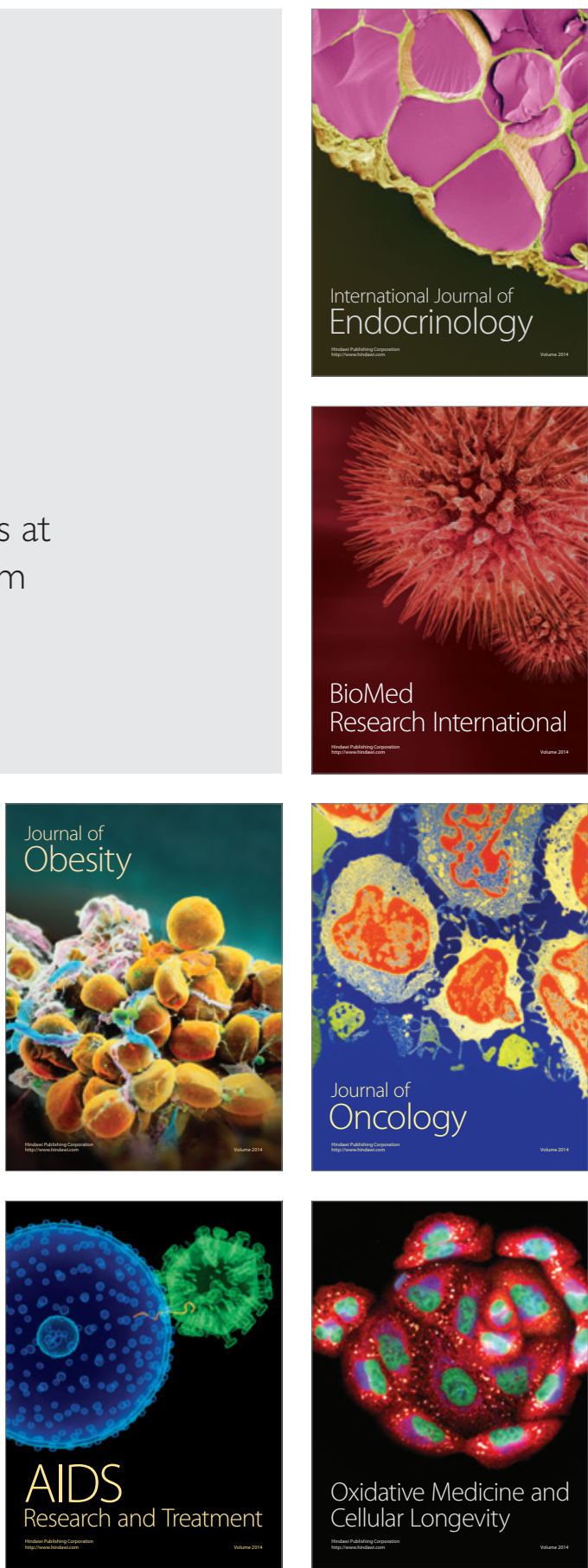